can be undertaken directly after the shaking without transferring the whole sample to another vessel.

The writer believes that his method is better than the one used by the Bureau of Soils in two respects. In the first place the machine is simple and inexpensive. A greater advantage is the saving of time. Clean separations can be effected in three hours, and in some cases two hours: this is a saving of at least four hours over the Bureau method. If the quantity of the water used in the bottles is reduced one-half, a clean separation results in much less than three hours, but there is a tendency for the grains to suffer some abrasion. SHEFFIELD SCIENTIFIC SCHOOL

YALE UNIVERSITY

New Haven, ConN.

\title{
ADDRESSES
}

\section{THE PRESENT STATUS OF THE WOOD TURPENTINE INDUSTRY ${ }^{1}$}

By E. H. FRench and James R. Withrow

In treating a subject that has as many phases as this one, it will be necessary to discuss briefly an allied industry, namely, that of Gum Turpentine as distinguished from Wood Turpentine, in order that the reasons calling for the development of this latter industry may be seen with the proper perspective.

That the Wood Turpentine Industry is at present at an extremely low ebb is unquestionably true. Nevertheless, it is likewise true that its scientific development is an economic necessity for certain localities, in order that waste may be conserved, that the products from waste replace those from the fast disappearing pine and fir forests and that cut-over land may be cleared at a profit instead of at a loss. Therefore, in this instance, as is often the case, necessity compels development.

The fact that thousands of dollars have been expended and lost in the incubation of this industry has been due, in our opinion, to three main causes, any one of which in itself would account for failure: first, the lack of practical scientific engineers experienced in this or analogous fields; second, financing for the sale of stock and securities rather than product; and third, lack of efficient marketing organization. It must also be borne in mind, that owing to the number of different processes, there was caused a lack of uniformity of product, which naturally tended to increase selling costs. Except to the U.S. Navy, little, if any, wood turpentine has been sold on thorough specifications. There has as yet been no real attempt by manufacturers to effect a general standard, although a few years ago the producers of the practically defunct steam process turpentine did make an attempt to standardize their product.

One of the important influences that tended at first toward the development of the industry and later proved extremely detrimental, was the speculative nature of the naval stores market. This was made up entirely of gum turpentine and rosin, upon the prices of which the relative wood turpentine values were determined. This market in the past has been subject to violent price changes, a fluctuation of from 30 cents to over $\$$ I.OO per gallon having been experienced, which was due almost wholly to speculation. Naturally, therefore, during the upward swing of prices an unnatural development occurred, and plants using costly processes and with inefficient management were profitably operated and exploited. It followed, of course, that when the national government, through criminal prosecution, put a stop to excessive speculation, a corresponding reaction occurred, ruining many concerns which required abnormal prices for financial success.

Unreasonably high prices not only encouraged the development of the wood turpentine industry, but also caused an expansion in operations by the gum turpentine manufacturers so that a larger percentage of trees, and many very young trees, were boxed, causing overproduction.

1 Presented at the 6th Annual Meeting of the Amer. Inst. of Chem. Eng., The Chemists' Club, New York, December 10-13, 1913.
GUM TURPENTINE

The method of producing oil of turpentine from the resins of coniferous trees, consists in cutting a broad wedge-shaped notch or cup at the base of the tree and removing the bark immediately above the notch for about I 8 to 24 inches. The resin exuding from the peeled area runs into the cup at the bottom and is collected from time to time. Each succeeding season the barked area is increased until it reaches about the height of one's head, usually taking five or six years. As many as four "boxes" are thus cut on one tree, depending on its size, permitting only enough of the original bark to remain to prevent the death of the tree.

After collecting sufficient quantity of the resin, it is distilled in a copper still, usually a "fire still," equipped with a live steam jet or a water supply. The turpentine thus produced is not carried farther in any refining process, but is ready for the market. The residue in the still is the rosin of commerce and is barreled at the still. The dross obtained by filtering sticks, dirt, etc., from the rosin is in many places being* worked into cheaper grades of rosin. With rosin at an average price, it is generally figured that to make the operation profitable, about 42 cents per gallon must be obtained for the turpentine.

The marketing of the products is done through "factors" as they are called; that is, companies or individuals who contract with the producers for their output, supply them with funds for pay-rolls, etc., and advances when necessary. These "factors" take the product when produced, but usually have no other connection with the producer. Savannah, Georgia, is the leading naval stores center in the world and usually Savannah prices are accepted as the standard. Jacksonville and Pensacola, Florida, Brunswick, Ga., and New Orleans, La., are also large "factor" centers for this industry.

This method of producing turpentine is generally conceded to give the best turpentine and rosin, but unless more scientific methods are very widely adopted the time is rapidly approaching when it will be necessary to supply these products from another source, for present methods of operation are beginning to be looked upon as directly antagonistic to all ideas of conservation under American lumbering conditions, as they so weaken the trees that the loss from windfalls is extremely large. In fact, many large lumber companies have given up "boxing" for this reason, and also because they feel that the growth of the young tree is retarded.

Modifications of the old "boxing" methods are being used in some places. Metal cups are substituted for the box cut in the base of the tree and light chipping is being tried. It is claimed that the loss from windfalls is considerably reduced by some of these modern improvements. At least one large Southern Iumber company is at present experimenting on 5,000 acre units in order to determine definitely, if possible, the merits of these new cups and other modifications as to yield and influence on windfalls, and also to decide the effect "boxing" may have on finished lumber.

\section{WOOD TURPENTINE}

Wood Turpentine came into commercial notice about the year 
1900. The name was, and is, applied to the product obtained from dead and down timber, a waste product called "lightwood." The live or green wood is not so suitable for this manufacture, owing to the moisture content and also to the fact that the bark still remains. Stumps, however, are very valuable, as they contain a much larger proportion of resins than "lightwood." Nevertheless, the cost per cord of stump wood is considerably more, as the stumps usually require the additional expense of removal by explosives. The cost per cord of "lightwood" at the works will run from $\$ 2.00$ to $\$ 3.00$, making, however, no allowance for its value as waste; while stump wood will vary from $\$ 3.50$ to $\$ 5.00$ per cord, the price depending on acre stumpage and hauling distances. The manufacture may be divided into five general processes; steam process, solvent process, alkali process, bath process and distillation process.

Before entering into a description of these various methods we desire to emphasize the statement that the manufacture of wood turpentine necessarily will become of far-reaching importance in the future. This is for the reasons that it is utilizing an absolutely waste product and is at the same time clearing cut-over lands and rendering them fit for occupancy. We wish also to emphasize the statement already made that many past failures were due to the unreasonable speculative condition of the markets. Abnormally high prices of naval stores induced promoters and unscrupulous persons to capitalize their concerns on the earning capacity during this period, thereby making them "stock jobbing" propositions rather than legitimate manufacturing institutions. This kind of financing while apparently expanding the industry really retarded development, as the energies of the management were expended primarily in the office and at the expense of the manufacturing organization.

We have seen from time to time figures of promoters, regarding yields and manufacturing costs of the different processes, which are not in accord with the results obtained from continuous operations. It may not be entirely without value therefore to cite some comparative yields and operation costs in these different processes, especially since there does not appear to be any published data of this nature. While the records themselves of individual plants would be interesting, such records are of ten misleading and in view of actual or possible competition, the location of plants must be withheld.

In submitting data as to yields, values and productive costs, we have complied them mainly from the actual results obtained during continued operation of a number of large plants. As so many elements making up these figures are variable, owing to location, construction and raw material, our endeavor has been to average them so that a comprehensive idea may be had as to actual results obtained commercially.

\section{STEAM PROCESS}

This process was the first to be extensively placed in commercial operation, and is very simple in its construction and handling. It consists merely of "hogging" the wood and placing it in a steel cylinder, holding usually about a cord, distillation being carried on with live steam and under varying pressure. However, there probably was little difference in results whether a maximum of five pounds or twenty pounds pressure was used. Distillation was carried forward until oils ceased to be obtained in quantity.

It should be borne in mind that there is a decided variance in the resinous content of wood; therefore, it was quite possible to make a selection that would run as high as 30 gallons of turpentine to the cord. We believe the following figures, however, based on a cord of long leaf yellow pine lightwood, weighing 3500 pounds, would be the average.

The fuel cost is only the labor of handling the treated chips. However, there is no allowance made for the office, upkeep, depreciation, insurance, etc. Therefore, it can be seen that the steam process, in order to be profitable, necessarily demands a market price considerably in advance of the present markets. The price of Wood Turpentine is always a few cents per gallon under that of Gum Turpentine. The quality of the product

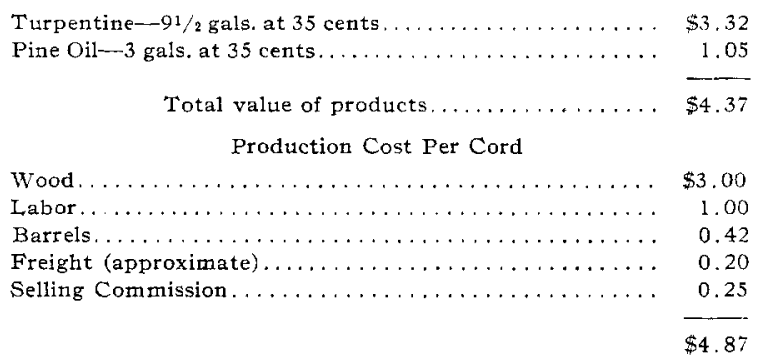

produced by the steam process, however, is excellent. Our opinion is, nevertheless, that at least 50 cents per gallon is necessary as a minimum for successful operation.

SOL,VENT PROCESS

In the early development of this process the wood was subjected to the old steam treatment and subsequently treated with carbon disulfide for the recovery of rosin. The loss of solvent rendered it impractical. In the next stage of development the wood was hogged and placed in digestors for the recovery of turpentine and pine oil. Then the solvent (a low grade of gasoline) was added, live steam was applied recovering some turpentine, pine oil, and solvent by distillation and the dissolved rosin drawn off, its volatile matter being recovered by distillation. This has been improved, in some instances, by omitting preliminary steaming, adding solvent direct and recovering this with the turpentine and pine oil by live steam in the primary distillation, obtaining rosin alone when the still is drawn. The rosin, however, is soft, and difficulty has been experienced in obtaining a hard product, but this is overcome by subsequent treatment. In either method a considerable loss of solvent is always entailed, varying from 17 to 30 gallons per cord. The approximate yields and operating costs per cord are as follows:

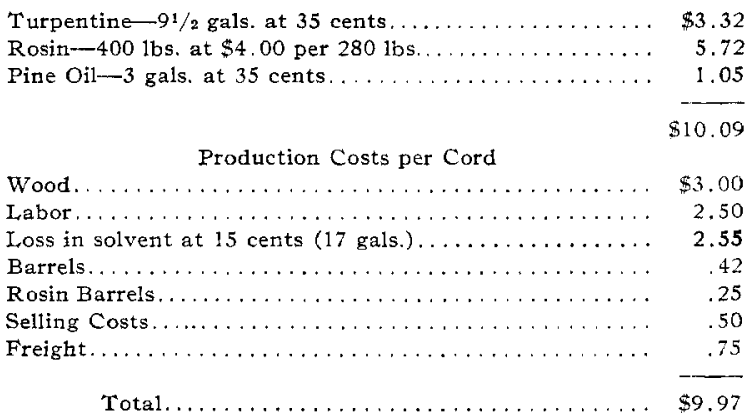

Again the actual fuel cost in this process is negligible as use is made of the "treated chips." No allowance is made here for insurance, upkeep, overhead and interest charges, refining costs or depreclation; therefore, it is plainly evident that, at present market prices, at least until improvement is made in yields or in minimizing costs, there is not sufficient margin for successful operation. However, it is quite possible that by using the "treated chips" for paper pulp manufacture this process can be made of commercial value. The operation in this case would have to be maintained on an enormous scale in order to supply treated chips for a pulp plant unit of an economic size. A plant using this solvent system and built on a very elaborate scale, was in operation in southeastern Georgia, and, despite the most advantageous financial backing, was unable to operate profitably on a weakened market, and is now in the hands of receivers. This citation alone probably would not necessarily condemn the process, but as several smaller plants are either in like position or shut down, it indicates the necessity of research or development if ultimate success is to be attained. As with the steam 
process, many claims of higher yields than we have above credited are made by interested parties, but these claims are still subject to substantiation.

\section{ALKALI PROCESS}

This process is essentially one to be applied to the alkali processes for manufacturing paper pulp from resinous woods with the recovery of turpentine and rosin and at the same time improving the quality of the pulp, and promoting ease of manufacture. The process is well covered by patents.

The basis upon which this method rests is the fact that the sodium hydroxide saponifies the resins in the wood and the sodium resinate thus formed may be separated from the spent soda pulp liquor by temperature regulation. The wood is handied in the same manner as in soda pulp manufacture, except that after digestion the spent liquor is cooled for the separation of sodium resinate before the liquor proceeds to the evaporators. This product has been so purified and refined, commercially, as to produce a good quality of paper size. The resinate may if desired be manufactured into resin by acid treatment, or destructively distilled to produce rosin oils. The turpentine is recovered from the digester blow-off during the digestion operation. This process is apparently theoretically sound, but requires the outlay of capital to develop thoroughly the mechanical details. Fifty to seventy thousand dollars were expended in one case to demonstrate its commercial possibilities and some results were obtained. However, the enterprise has not been financially successful and the plant has been dismantled, a fact which may be due to faulty engineering or other causes; and even though the process appears enticing from a theoretical viewpoint the fact remains that the trial was not successful and there is no process of this kind in actual operation. Nevertheless, it is our opinion that eventually it will be of commercial importance and ultimately the combination of the two industries, paper pulp and turpentine-rosin recovery, thus utilizing resinous wood, will be successful. Unusual yields of turpentine are claimed by a Florida plant using an alkali bath but satisfactory arrangements have not yet been made regarding rosin recovery. BATH PROCESS

This process must not be confounded with the recently suggested process using a bath or envelope of oil externa1 to the oven for the purpose of heating the same. This external bath process has not been long enough in operation to demonstrate its future and it will be interesting to note whether certain fundamental operation difficulties can be overcome.

By Bath Process we refer to the process commercially so called which has been in operation for some time and in which the bath is within the oven or retort in contact with the wood itself. Three plants using this method have been built, the first in North Carolina, which has been dismantled, the others at Mt. Pleasant, Georgia, and Jacksonville, Florida, which have not been successful owing to low market conditions and both of which have gone into receivers' hands within the last few months.

The process itself was divided into two separate general operations: first, the recovery of turpentine and pine oil, or "sweet spirits," and subsequently the destructive distillation of the wood itself, although this second operation was not contemplated in the original process.

The operation has a decided advantage over the solvent and steam processes in that it does not require the "hogging" of the wood.

The general construction used in this first operation consists of steel cylinders at $\mathrm{Mt}$. Pleasant, and concrete ovens at the Jacksonville plant, each holding five to nine, one or two cord steel cars, similar in construction to those in common use in hard wood distillation; thus each oven holds about nine cords of wood. Placed at the side of the oven is a heater equipped with a large cast iron worm joined to the bottom of the oven. To the rear of the heater is placed a large steel or concrete reservoir connected by cast iron pipe with the top of the oven, and also with rotary pumps which in turn are joined to the heater pipes.

The loaded cars are placed in the oven and melted rosin or pitch is run into the reservoir and circulated by the pumps through the heater and the bottom oven connection. This pitch after filling the oven in contact with the wood overflows into the reservoir and is thus continually circulated through the heater and oven, thereby vaporizing the volatile resinous bodies, without dissociating the wood fiber. The turpentine and oil vapors are carried through a "vapor" chamber in which the high boiling liquids that are mechanically carried by the vapor are separated, the vapor continuing to an ordinary tubular condenser, where the crude "sweet spirits" are obtained. Afterwards the "sweet spirits" are refined, the products being turpentine, pine oil and a tarry residue. The time required to treat a charge varies in the plants mentioned from seven to ten hours, and the product obtained is of high quality, though not so good as steam process turpentine.

At first sight it would appear that in this process the rosin from the wood treated would gradually increase the volume of the bath and rosin be thus manufactured. The reverse of this, however, is the case, as a serious loss of bath is actually realized. This is in fact a very serious drawback to the process, and is probably due to the formation of volatile rosin oils when the liquid bath encounters the high temperature of the heater. These rosin oils are volatilized and pass into the "crude spirits," and are lost in the refining residue, as only from 65 to 70 per cent of the spirits is received as turpentine and pine oil. By proper arrangement this difficulty could be avoided.

This process is also seriously handicapped by the fuel consumption of the heaters and the heavy upkeep for heater pipes and pumps. Nevertheless, with proper design, operation costs would be much reduced from that actually experienced.

After refining, the results from this "sweet process" could be averaged as follows:

$$
\begin{aligned}
& \text { Turpentine, } 71 / 2 \text { gals. at } 35 \text { cents } \ldots \ldots \ldots \ldots \ldots \ldots \ldots \$ 2.62 \\
& \text { Pine Oil, } 2.5 \text { gals. at } 35 \text { cents................. } 87 \\
& \overline{\$ 3.49}
\end{aligned}
$$

After the charge is withdrawn in this first operation the "treated" wood is placed in ovens similar to those used in the hard wood industry and there subjected to destructive distillation. The results obtained here are very important as a good market has been created for these products. An average of from 68 to 70 gallons of oils is obtained, together with a like volume of "acid water," the latter a "waste," although its utilization was accomplished just prior to the receivership of one of the mentioned companies. In addition there remains in the cars approximately 900 pounds of charcoal and there is produced about 10,000 feet of non-condensible gas per cord which is of fuel value.

This crude distillate above mentioned is called "destructive distillate" or "D. D. Product" to distinguish it from the product derived from the resins, called "sweet spirits." On refining there are obtained the following products per cord:

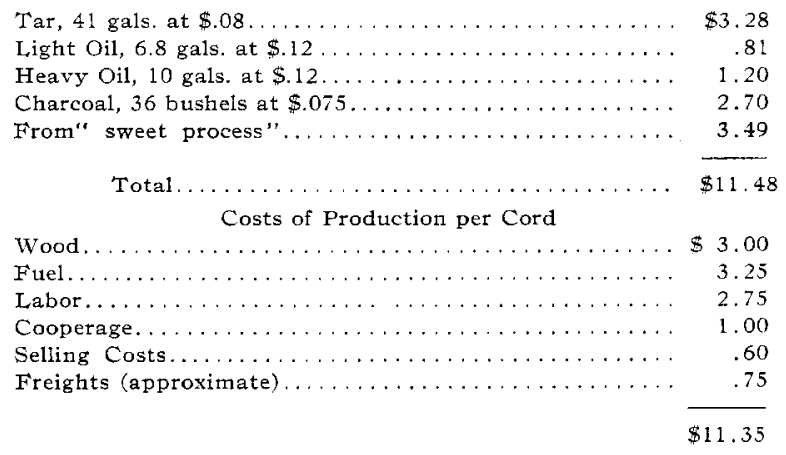

Again it can be seen that this process handled as it has been 
in the past cannot be operated successfully on a low market, as no allowances have been made for upkeep, insurance, interest charges, refining costs, management or depreciation. Although the loss in bath is partially made up by the pitch obtained, it can be seen from these costs that improvement must be had before this process can exist during low market conditions. It is not to be inferred, however, that the principles upon which the process is based are entirely faulty. The reasons for its failure appeared to be lack of knowledge as to the chemical nature of the products and troubles consequent to improper construction and operation. As is common with approaching dissolution strenuous efforts at improvements were made in this process, and despite well known prior failures, experiments were completed and operation commenced for the utilization of the waste "acid water" just before the closing of one of the plants. The results proved interesting and promised excellent recovery, as the products recovered, including acetate of lime and wood alcohol, represented a net gain of well over $\$$ I.50 per cord.

\section{DISTILLATION PROCESS}

As the wood turpentine industry now stands, the destructive distillation process apparently has the best chance of commercial success, as it is not only more simple in construction and operation, but yields more in volume of products. Chemical and engineering skill, nevertheless, are necessary for this success.

The distillation process may be subdivided into three divisions: first, that division analogous to hard wood distillation. This method in its primary operation is very similar in equipment and design to the usual hard wood distillation plant, the wood being placed in steel cars and run into ovens. The products derived from the resins and those from the dissociated wood are collected together, and separation is made during refining, although some attempt has been made at fractional distillation in this primary stage. This method gives a much inferior grade of turpentine, etc., owing to the commercial difficulty of eliminating the pyroligneous bodies, and the product will not answer to the permanganate test which indicates pyroligneous matter. The tar produced in this operation is usually resinous and for some uses, therefore, objectionable.

The second division is merely a modification of this process, the ovens being in duplicate, and distillation for the resinous bodies being carried out in one oven, so designed or "set" that the temperature can be maintained approximately uniform. After the resinous bodies have been obtained the "treated wood" is withdrawn and placed in a second oven and in this oven the distillation is carried at a higher temperature for the destructive distillation of the wood itself.

The third division is that using concrete ovens containing I 2 inch heater pipes running the length of the ovens. These ovens have dutch-oven connections and the flue gases travel through these pipes, and it is claimed that temperature regulation is more easily accomplished.

In all these processes the products obtained are the same, except so far as the degree of purity is concerned.

The first distillate, or that from the resins in these methods, will run on an average 22 to 24 gallons of "sweet spirits." This on refining will give from 50 to 60 per cent or from 12 to I4 gallons of marketable turpentine and from 9 to Io per cent or from 2 to $2^{1 / 2}$ gallons of pine oil, and also roo pounds of a very resinous pitch.

The destructive products are the same as those from the "bath process;" thus it can be seen that the gross total in this operation should be materially higher than in the other processes, while the operating expense is very much lower. This, including wood, upkeep, and in fact all expense, should not, under proper design, construction and management, run over $\$ 9.00$ a cord.

The particular objection raised against the destructive distillation process is that the products are difficult to market, and this has been true to a certain extent in the past, but when it is considered that many of these products were new to the trade this condition cannot be wondered at, and at present the marketing is not more difficult than products of other processes. In fact, just now there is an unusual demand for these products.

MARKETS

It may, perhaps, be of interest to call attention to the various developed markets for the $\mathrm{D}$. D. Products, for we all realize that the marketing of products is at least equal in importance to the manufacture; and this industry shows many instances where comparative merit of process and operation was wholly lost by inferior marketing facilities, and, on the other hand, instances in which unsound operation was maintained for a considerable time by a remarkably efficient selling organization. The latter cases, while losing ventures to those financially interested, have no doubt succeeded in creating a growing demand for the products, as indicated by the prices now obtained for them, with many plants closed down. At the present time tar could be easily sold for 12 cents per gallon as compared with the 8 cents allowed in the cost data in this article, but which should be considered maximum, as the future will undoubtedly increase supplies so as to bring these prices back to a more nearly normal condition. This fact, however, does show that a demand has been created that did not exist prior to the quite recent establishment of plants of this nature. Perhaps this condition is more clearly evidenced in the heavy D. D. oil, for which 22 cents per gallon is being obtained. The tar demand had in a measure been previously supplied by that known as "kiln tar" made at works using the kiln system for charcoal manufacture from resinous woods.

The product mentioned as D. D. light oil is at present most difficult to market profitably. It is on the market in this form and is used to some extent by manufacturers of disinfectants. However, it has been fractionally distilled and has been used locally as a substitute for gasoline for use in engines and has proven itself to be more efficient than gasoline. The comparatively small amount of this product makes its ise in this manner merely of local interest but it indicates a real value of the product.

The heavy D. D. oil has been in consistent and increasing demand, particularly in the paint industry, and notably for shingle stains; also for the manufacture of tar oils for which there is a large foreign demand. The necessity of an energetic market agency for this product was in one case well illustrated within the past year. One large concern, having nearly Ioo,ooo gallons in storage, and finding it impossible to market, was offering it for 5 cents per gallon, while at the same time another company was unable to supply its customers at 18 cents per gallon. Of course, the latter considered the purchase from the former, but feared future competition in case, as seemed dangerously probable, the former concern should learn of their customers.

The pitch produced in the distillation process and distinguished from the tar has a firm market demand from ship chandlers and also is sold for uses such as coating silos, rendering them impervious to moisture.

The tar, of course, has its established used with rope manufacturers as well as with paint producers, while the charcoal consumption, particularly in the south, is very steady both for domestic use and manufacturing. Of the number of suggested specialties based on the use of tars and oils, doubtless a few will ultimately contribute a steady demand for a portion of these products.

\section{COSTS OF INSTALIATIONS}

The various processes have in most instances exceeded reasonable installation costs. Undoubtedly the same is true in any newly established industry, and more particularly in cases where, as pointed out in this one, prices could be obtained that were out of all proportion to production costs. 
The entire equipment of a steam process plant should come well within $\$ 750.00$ per cord capacity, while the solvent process complete should be approximately $\$ 2,000.00$ per cord. This also should be approximately that of the bath system, while the destructive distillation method ought to be very close to \$1500. In making these general estimates neither working capital nor purchase of timber or stumpage is considered.

\section{CONCLUSION}

When your attention is brought to the fact that the destructive distillation plants alone have been able to survive recent price depression, it is reasonable to conclude that, in the present state of the art, this method has inherent advantages. Nevertheless, in this type of process there is room for much improvement, particularly in refining and the utilization of waste products that were ignored in the past. Constructive chemical engineering in this industry apparently has opportunity to create an unusually profitable business, provided it utilizes the unfortunate mistakes of the past, by combining parts of the various processes.

It is not to be inferred from this article that recommendations are made for the encouragement of any particular process. The motive is merely to outline present conditions or, broadly, to show cause and effect; and also to show, if possible, that in order to attain success, many elements are as necessary in this industry as in any other. Statements have been made to the effect that failures in most instances were due to lack of real engineering skill, and this is partly true, but lack of skill is not wholly accountable for even the engineering failures, as no amount of theoretical engineering skill can replace the knowledge acquired from continued intimate contact with the going operation.

Neither does this statement take into consideration the marketing organization, which is also an essential, and is always confronted with the general economic situation, although this does not affect directly the operation.

It can be seen from this outline of the industry that its very existence was primarily due to an unnatural market condition, and as the field for profit and exploitation was so enormous it can hardly be wondered at that there was unusual activity in its promotion.

OHIO State UNIVERStTy, Columbus

\section{CHEMISTRY AS AFFECTING THE PROFITABLENESS OF INDUSTRY ${ }^{1}$}

By G. W. Thompson

In the preparation of this paper I had thought of considering chemical industry as if it were distinct from other industries, but, as the subject developed, it became very apparent that no such distinct line could be drawn. Properly speaking, all industries must be considered as chemical. It is next to impossible to imagine the existence of an industry in which chemical reactions or considerations, either directly or indirectly, do not enter. It is possible that we could define chemical industry in a somewhat restricted sense, but such a definition would hardly be other than arbitrary. The lines of demarcation would be indistinct and shadowy. The only basis for such a definition would be the attitude of the popular mind. This attitude of mind has been steadily growing towards the recognition of the fact that chemistry is an important factor in every industry, and when, in any particular case, it becomes popularly recognized that chemistry is a factor in an industry, then that industry becomes a chemical industry. Ultimately, this popular recognition will extend to all industries and the rapidity of the growth of such recognition indicates that the time is not far distant when all industries will be generally and popularly recognized as chemical.

My plan had been to discuss the profitableness of chemical industry, but if we accept the conception that all industries are chemical, it would seem better that our discussion should be

I Chairman's Address before the New York Section of the Society of Chemical Industry, The Chemists' Club. October 24, 1913. broadened so as to consider the general effect of chemistry upon the profitableness of industrial operations, using the words "industrial operations" as including all phases of the actual production of wealth.

Perhaps it would be well to make clear the conception that all industries are chemical in one or more phases. By way of illustration, let us consider the relation of chemistry to the production of power. I think we can show that there is a very close connection between chemistry and such production, and also that there is no industry which does not depend upon the consumption of power; this being the case, it becomes very evident that, from the power standpoint alone, all industries are chemical industries.

Our first impressions of power are those which we ourselves are conscious of exercising, and, in practice, the simplest form of power is man power as manifested in manual labor. It is not customary, perhaps, except from the humanitarian standpoint, to consider the chemical changes in the human body, converting food into work, as factors in industry. Nevertheless, they deserve serious consideration. It is being learned daily that properly fed employees are more efficient as workmen, and the study of food problems is surely a phase of the application of chemistry to industry. In some industries, the study of the food consumed by employees has a direct bearing upon the health of the employees as affected by the industry. It is found that certain foods act as prophylactics towards certain industrial diseases, and that other foods (perhaps improperly so called) act in the opposite manner. The scientific study of foods in connection with efficient manual labor is a phase of welfare work that has not been considered to the extent it deserves. Take, on the other hand, the horse. It is true that the horse is being displaced by the locomotive and automobile, and as a power factor, has been almost completely superseded by mechanical appliances; still, so far as the horse is used for the power he furnishes, his proper feeding is a phase of the application of chemistry to industry. Perhaps it may be considered that these two illustrations, the feeding of employees and the feeding of horses, are trivial as compared with the study of the production of power through the use of the steam boiler, the steam engine, the gas producer, and the internal combustion engine. Probably this is so, for, in the production of power by these mechanical means, we have clearly recognized chemical reactions, and the understanding of these chemical reactions is essential to the proper economy of fuel and the production of power with the least outlay. In these cases, chemistry teaches us the need of a proper balancing of the combustible material used and the air supply, so that the loss of heat in effluent gases may be reduced to a minimum. In the steam boi'er, chemistry has taught much of great value in relation to the refractory materials used, the utility of water consumed, and how to correct its scale-forming tendencies. In recent years, numerous excellent devices have been developed for automatically giving information as to the composition of flue gases, with the result that great savings in the cost of power have been made. The study of the composition of coals has resulted in a better classification of coals, a truer connection between price and quality, and the purchase of coals by specifications involving chemical examination is becoming more extensive each year. The small power plant cannot perhaps give as much attention to chemical factors as can a large plant, but in large power plants, the economy resulting from the study of the chemistry of combustion has enabled such plants to furnish power to outsiders with a profit to themselves and to those to whom they sell it. Chemical considerations led to the use of blast furnace gases in the gas engine for the production of power; and if the chemist's dream comes true, there will come a time when power will be more directly produced from coal than it is to-day. It is, of course, recognized that in the utilization of the energy in our 